\title{
Peripheral Neuromodulation and Headaches: History, Clinical Approach, and Considerations on Underlying Mechanisms
}

\author{
Ken L. Reed
}

Published online: 29 December 2012

(C) The Author(s) 2012. This article is published with open access at Springerlink.com

\begin{abstract}
Implantable peripheral neurostimulation was introduced in 1969 as a potential treatment for certain neuropathic pain syndromes, primarily involving the limbs. While a few early studies included implants for occipital neuralgia, serious interest in its potential as a treatment for head pain came only after our 1999 report of positive findings in a series of patients with occipital neuralgia. Subsequent investigators confirmed these initial findings, and then extended the application to patients with various primary headache disorders, including migraine. While most found a therapeutic response, the degree of that response varied significantly, and analysis suggests that the issue of paresthesia concordancy may be central, both in explaining the data, as well as providing direction for future endeavors. Therefore, while at present peripheral neurostimulation is gaining increasing acceptance as a treatment for chronic headaches, the precise clinical indications and procedures, as well as the underlying neurophysiological mechanisms, are still being worked out.
\end{abstract}

Keywords Neurostimulation - Neuromodulation ·

Peripheral nerve stimulator · Occipital neuralgia - Occipital nerve, trigeminal nerve, migraine $\cdot$ Hemiplegic migraine $\cdot$

Cluster $\cdot$ Supraorbital $\cdot$ Paresthesia $\cdot$ Trigeminocervical complex $\cdot$ Positron emission tomography $\cdot$ PET scan · Neuropathic pain $\cdot$ Chronic pain, chronic migraine

This article is part of the Topical Collection on Chronic Daily Headache

K. L. Reed $(\bowtie)$

Reed Migraine Centers, 11970 N Central Expy; Ste 510,

Dallas, TX 75243, USA

e-mail: klreed1@swbell.net

\section{Introduction}

Migraine is a common disorder of the brain that exacts a significant toll on the human condition. It afflicts at least $4 \%$ of the population and dramatically impacts function in terms of lost school and workdays [1]. The burden on patients and society increases if the migraine becomes chronic, a cohort in which over $50 \%$ of patients feel their treatment to be unsatisfactory [2]. Recognizing and responding to this clinical challenge, over the past two decades professionals have developed various implantable neuromodulation techniques and evaluated these as potential treatment alternatives in this unfortunate patient population. Here we review the significant aspects of peripheral neuromodulation for headaches, including its genesis and history, relevant clinical considerations and procedures, as well as the work that has been done to elucidate possible underlying mechanisms of action. Finally, considerations are offered as to potential directions for future investigations.

\section{History of Neuromodulation and Headaches}

With the publication of their "Gate Control Theory" of pain modulation in 1965, Wall and Melzack provided a conceptual mechanistic foundation for considering direct electrical stimulation of the spinal cord and peripheral nerves as a potential treatment for chronic pain [3]. The prophetic nature of this work was redeemed in 1969, when Shealy described positive responses in patients implanted with spinal cord stimulators (SCS), and Long implanted the first commercially available peripheral nerve stimulators [4]. Thereafter, the bulk of clinical investigations involved various applications of implantable SCS for chronic back and extremity pain, and indeed, over the years SCS has become widely accepted as a standard treatment methodology for some patients with chronic back and extremity pain unresponsive to more conservative measures [5]. 
Peripheral nerve stimulation (PNS) therapies for chronic pain developed in parallel to SCS, albeit somewhat more slowly. Over the 1970s and 1980s, Long, Nashold and others documented favorable responses to open surgical PNS implants in patients with various neuropathic pain syndromes, most commonly of the limbs [6-11]. While a few studies included isolated patients with occipital neuralgia, serious attention to the potential of this methodology as a treatment for head pain came only after 1999, when we presented implanted occipital nerve stimulators (ONS) with percutaneously placed leads as a novel therapeutic treatment for intractable occipital neuralgia [12••]. Thereafter, interest in the technique spread rapidly, and subsequent investigational work developed primarily along two clinical avenues-PNS for cephalic neuralgias, and PNS for primary headaches, the findings of which are summarized in Tables 1 and 2.

\section{PNS and Cephalic Neuralgias}

Our report on ONS for occipital neuralgia was quickly followed by a myriad of studies evaluating its application to various neuropathic maladies afflicting the occipito-cervical region, including occipital neuralgia, cervicogenic headache, and other intractable C-2 mediated headaches [13-18, 19•, $20 \bullet, 21,22 \bullet$. All groups reported consistent, remarkable success rates on the order of 70-100\% (mean 89\%) (Table 1).

Over this same period, other investigators applied supraorbital nerve stimulation (SONS) to neuropathic pain perceived over the frontal region and found similar results. In 2002, Dunteman reported successful treatment of two patients with ophthalmic post herpetic neuralgia with an implanted supraorbital nerve stimulator [23]. Succeeding Dunteman were a host of investigations that applied PNS to supraorbital and other painful trigeminal neuralgias, as reported on by Johnson (2004), Slavin (2006), and Amin (2008), who all found longterm $70-100 \%$ success rates $[22 \cdot, 24,25]$. Yakolev extended the indications in 2010 when he successfully treated a patient with atypical facial pain with subcutaneous, octipolar arrays over the mandible [26]. In 2012, Stidd had two patients with trigeminal neuralgia respond well to combined SONS and infraorbital nerve stimulation (IONS) [27]. Evaluating these studies as a whole, we find virtually the same success rates of 70-100\% (mean $88 \%$ ) as we do with ONS and occipital pain.

Therefore, on the one hand, it's interesting that the reported response rates from the groups treating facial pain with peripheral trigeminal stimulators are virtually identical to the corresponding rates reported by those treating occipital pain in the same manner $(70-100 \%$ success rates). However, this should not be surprising, as it is in line with, and essentially an extension of, the well-documented effectiveness of implantable neurostimulators for analogous painful neuropathies over the torso and the limbs. Indeed both groups, neurostimulation is being applied to the same underlying problem of neuropathic pain, just over different neural distributions.

PNS and Primary Headaches

\section{Occipital Neurostimulation and Headaches}

The initial applications of PNS to cephalic pain continued in line with the historical standard of neuropathic pain until 2003, when Dodick described a positive response to ONS in a patient with cluster headaches, and Popeney found similar results in a series of patients with transformed migraine $[20 \bullet \cdot, 28 \bullet \bullet]$. These were the first reports on the use of PNS for primary headaches, i.e., disorder of the brains, as opposed to a peripheral neuropathic pain, and they generated wide interest in the potential of this methodology. As such, the succeeding years witnessed a series of increasingly sophisticated studies evaluating the responsiveness of primary headaches to ONS, with the corpus of work primarily focused on cluster and chronic migraine headaches [Table 2].

With respect to cluster headaches: following Dodick's 2003 report on ONS, most of the clinical work was published by seven different teams, who on average reported a $62 \%$ response rate, which was notably lower than those rates seen when neurostimulation was applied directly to the area of pain, e.g. the over $90 \%$ rates found with PNS for occipital and various trigeminal neuralgias [29-38].

Arguably the most interest with respect to ONS and primary headaches has centered around migraine. Beginning in 2003, an initial series of relatively small studies documented positive results [19•, 35, 38, 39], and ultimately, each of three primary manufacturers undertook large, multicenter, randomized, double-blinded, prospective studies evaluating the responsiveness of chronic migraine to ONS. These included Boston Scientific's PRISM study (125 pts), St. Jude (105 implants; 52 controls), and Medtronic's ONSTIM study (33 implants, 34 controls) $[40 \bullet, 41 \bullet \bullet, 42 \bullet \cdot$. Using the historical standards for a positive response of over $50 \%$ improvement in either pain level or frequency, both the Boston and St. Jude studies found no evidence for a significant positive therapeutic result. St. Jude did note, however, significant reductions of the VAS and HA days/mo at approximately the $30 \%$ level and that overall $52 \%$ of patients were satisfied at 12 weeks [41••]. Indeed, Medtronic was the only to find a significant result in a primary variable, as they reported a $39 \%$ response rate at 3 months (vs. $<6 \%$ of controls; $p<0.05$ ) [42••]. Now, even this $39 \%$ rate needs be qualified, as a $30 \%$ improvement in pain was used to define a responder, rather than the standard $50 \%$. 
This is very important, as the clear clinical standard used to define a positive response to a trial stimulator is over $50 \%$ improvement. Thus, of the three largest, double-blinded, prospective studies that have been performed to date on ONS and migraine, two found no significant support for an adequate therapeutic effect, and the other found only a very qualified $39 \%$ success rate.

\section{Supraorbital Neurostimulation for Headaches}

In 2009, Narouze published the first successful application of supraorbital nerve stimulation for cluster headaches, using NS implant protocols similar to those applying ONS to cluster headaches [43•]. In 2012, Vaisman fortified the validity of this technique, when he found

Table 1 Summary of patients treated with concordant neurostimulation

\begin{tabular}{|c|c|c|c|c|}
\hline Report & Dx & No Perm & Resp Rate & Notes \\
\hline \multicolumn{5}{|c|}{ Occipital Neuropathic Pain Treated with ONS Alone } \\
\hline Weiner, Reed $[12 \bullet \bullet]$ & ON & 13 & $80 \%$ & $80 \%$ had good to excellent relief \\
\hline Rodrigo-Royo [21] & ON & 4 & $100 \%$ & $97 \%$ avg decrease in VAS \\
\hline Kapural [16] & $\mathrm{CEH}$ & 6 & $100 \%$ & $70 \%$ avg decrease in VAS \\
\hline Slavin [63] & ON & 10 & $70 \%$ & All had excellent pain relief at 6 mo \\
\hline Johnstone [15] & ON & 7 & $71 \%$ & $73 \%$ avg decrease in VAS \\
\hline Melvin [17] & ON & 11 & $100 \%$ & $73 \%$ rated relief as good to excellent \\
\hline Shaldi [64] & $\mathrm{ON}$ & 8 & $88 \%$ & $71 \%$ avg decrease VAS \\
\hline Magown [65] & ON & 7 & $100 \%$ & 6 had $75-100 \%$ improvement \\
\hline Vadivelu [66] & $\mathrm{AC}$ & 15 & $87 \%$ & All had over $50 \%$ improvement \\
\hline Pameliere [19•] & $\mathrm{NC}$ & 8 & $100 \%$ & $80 \%$ avg relief \\
\hline $\mathrm{Oh}[15]$ & $\mathrm{ON}$ & 10 & $\begin{array}{l}100 \% \\
89 \% \text { avg }\end{array}$ & All had $90-100 \%$ relief \\
\hline \multicolumn{5}{|c|}{ Trigeminal Neuropathic Pain Treated with Trigeminal Stim Alone } \\
\hline Dunteman [23] & PHN & 1 & $100 \%$ & $\mathrm{SON}$ \\
\hline Johnson, Burchiel [25] & TNP & 10 & $70 \%$ & I SON; 2 ION \\
\hline Slavin $[22 \bullet]$ & TNP & 7 & $82 \%$ & $4 \mathrm{SON} ; 3 \mathrm{ION}$ \\
\hline Amin $[24]$ & SON & 10 & $100 \%$ & SON \\
\hline Yakolev [26] & AFP & 2 & $100 \%$ & Subcu octrodes over mandible \\
\hline Stidd [27] & TNP & 3 & $\begin{array}{l}100 \% \\
88 \% \text { avg }\end{array}$ & $1 \mathrm{SON} ; 2 \mathrm{SON}-\mathrm{ION}$ \\
\hline \multicolumn{5}{|c|}{ Occipitally-Focused Migraine Headaches Treated with ONS Alone } \\
\hline Popeney $[20 \bullet \bullet$ & $\mathrm{TM}$ & 25 & $100 \%$ & $100 \%$ responded \\
\hline Oh [18] & $\mathrm{TM}$ & 10 & $90 \%$ & $90 \%$ had $>75 \%$ improvement at $3-6$ mo \\
\hline Matharu $[54 \bullet \bullet]$ & $\mathrm{CM}$ & 8 & $\begin{array}{l}100 \% \\
98 \% \text { avg }\end{array}$ & $100 \%$ had good to excellent relief \\
\hline \multicolumn{5}{|c|}{ Frontal (Cluster) Headaches Treated with Trigeminal Stim Alone } \\
\hline Narouze $[43 \bullet]$ & $\mathrm{Cl}$ & 1 & $100 \%$ & SON stim \\
\hline Vaisman [44•] & $\mathrm{Cl}$ & 5 & $100 \%$ & SON stim \\
\hline Simopoulos [67] & $\mathrm{CM}$ & 1 & $\begin{array}{l}100 \% \\
100 \% \text { avg }\end{array}$ & ATN stim \\
\hline \multicolumn{5}{|c|}{ Hemicephalic/global (Chronic Migraine Headaches) Treated with Combined Stim } \\
\hline Reed $[45 \cdot \bullet]$ & $\mathrm{CM}$ & 7 & $100 \%$ & ON-SON stim \\
\hline Desphande $[46 \bullet]$ & $\mathrm{CM}$ & 1 & $100 \%$ & ON-ATN stim \\
\hline Mammis [47•] & $\mathrm{Cl}$ & 1 & $100 \%$ & ON-SON-ION stim \\
\hline Reed [54••] & $\mathrm{CM}$ & 44 & $\begin{array}{l}87 \% \\
89 \% \text { avg }\end{array}$ & ON-SON stim \\
\hline
\end{tabular}

$O N$ occipital neuralgia; TM transformed migraine; $C E H$ cervicogenic headaches; $D x$ diagnosis; $I C 2 H$ Intractable C-2 Headaches; $A C$ ArnoldChiari; $C M$ chronic migraine; ATN Auriculotemporal Nerve; $I O N$ infraorbital nerve; SON supraorbital nerve

Unless otherwise specified, all success rates indicate $>50 \%$ improvement in VAS or HA frequency 
Table 2 Summary of patients treated with non-concordant neurostimulation

\begin{tabular}{|c|c|c|c|c|}
\hline Report & Dx & No Perm & Resp Rate & Notes \\
\hline \multicolumn{5}{|c|}{ Cluster Treated with ONS Alone } \\
\hline Dodick $[28 \bullet \bullet]$ & $\mathrm{Cl}$ & 1 & $100 \%$ & HA free after $12 \mathrm{mo}$ \\
\hline Burns $[68,69]$ & $\mathrm{Cl}, \mathrm{HC}$ & 20 & $45 \%$ & 9 of $20 \mathrm{had}>50 \% \mathrm{imp}$ \\
\hline Magis [32] & $\mathrm{Cl}$ & 14 & $85 \%$ & $80 \%$ had $>90 \% \mathrm{imp}$ \\
\hline Trentman [38] & $\mathrm{Cl}$ & 5 & $60 \%$ & 3 had fair to exc resp \\
\hline Schwedt [35] & $\mathrm{Cl}$ & 8 & $60 \%$ & $60 \%$ had $>50 \% \mathrm{imp}$ \\
\hline de Quintana [29] & $\mathrm{Cl}$ & 4 & $100 \%$ & All had $>50 \% \mathrm{imp}$ \\
\hline Fontaine [30] & $\mathrm{Cl}$ & 13 & $77 \%$ & $77 \%$ had $>50 \%$ imp \\
\hline Mueller [34] & $\mathrm{Cl}$ & 10 & $\begin{array}{l}40 \% \\
62 \% \text { avg }\end{array}$ & All had $>50 \%$ imp in freq $/ \mathrm{sev}$ \\
\hline \multicolumn{5}{|c|}{ Chronic Migraine Headaches Treated with ONS Alone } \\
\hline Saper (Medtronic) $[42 \bullet \bullet]$ & $\mathrm{CM}$ & 51 & $39 \%$ & $39 \%$ had $>30 \%$ VAS imp \\
\hline Silberstein (St. Jude) $[41 \bullet \bullet]$ & $\mathrm{CM}$ & 105 & $35 \%$ & $35 \%$ had $>30 \%$ VAS imp \\
\hline Lipton (Boston Sc) [40•] & $\mathrm{CM}$ & 132 & $?$ & Statistical results not significant \\
\hline Pameliere $[19 \bullet]$ & MWA & 8 & $63 \%$ & $47 \%$ average relief \\
\hline Serra [39] & $\mathrm{CM}$ & 29 & $\begin{array}{l}100 \% \\
48 \% \text { avg }\end{array}$ & MIDAS, SF36, meds all stat sig \\
\hline Summary: & \multicolumn{4}{|c|}{$\begin{array}{l}48 \% \text { average response rate ( }>50 \% \text { VAS imp) for all chronic migraine studies } \\
37 \% \text { average response rate ( }>30 \% \text { VAS imp) for the "benchmark" Medtronic and St. Jude studies }\end{array}$} \\
\hline
\end{tabular}

$\mathrm{Cl}$ cluster; $\mathrm{CM}$ chronic migraine; $\mathrm{HC}$ hemicranias continua; $M W A$ migraine without aura

therapeutic responses to SONS in a series of five patients with cluster headaches [44•].

\section{Combined Occipital and Supraorbital Neurostimulation for Headaches}

Based on several convergent lines of consideration (see below), in 2006 we hypothesized that using combined ONS and SONS may be beneficial in some patients suffering from chronic migraine, where the pain is perceived in hemicephalic or global extent (and therefore involving both the trigeminal and occipital neural systems), and in 2009, we reported on strongly positive responses in a series of seven patients so treated. All were quite debilitated due to daily incapacitating migraine, and all responded, with six describing near complete resolution of the headaches (over $90 \%$ improvement). Notably, one patient's associated hemiplegia resolved as well [45••]. In 2011, Deshpande and Mamis presented independent case studies on similar combined approaches in patients with hemicrania continua (ONbilateral temple leads) and cluster headaches (ON-SONION leads), respectively [46•, 47•]. Also in 2011, Linder was the first to report on combined ON-SONS in adolescent patients, finding therapeutic responses in 11 teenagers [48 ${ }^{\bullet}$. In 2012, Datta first described the successful employment of combined ON-SONS in a patient with severe migraine who was post surgical decompression of the occipital nerves [49•]. Finally, in 2011 while compiling outcome data on a larger clinical database, our group presented in abstract positive results in a series of 44 patients treated with the same combined ON-SONS system [50•].

\section{Historical Data Analysis and Issue of Concordancy}

\section{Paresthesia Concordancy}

When implanting neurostimulator leads, the clinical standard has always been to seek a concordant paresthesia; that is, to effort a neurostimulator induced paresthesia that, as best as possible, covers the anatomic region of perceived pain, which is the clinical indicator that the correct portion of the nervous system is being stimulated [5]. For example, when implanting a SCS in a patient with low back and right leg pain, the technical goal is to place the leads in such a manner as to have the paresthesia perceived over the same regions of the low back and right leg. Indeed, the current standard during all neurostimulator implants is to test the system "on the table" by arousing the patient enough to report the paresthesia location, whereby the surgeon adjusts the lead tips to optimize that coverage. In fact, we are not aware of any reports prior to 2003 where a stimulator was 
intentionally placed in a manner that did not seek a concordant paresthesia. Even reports of neurostimulators in patients with cardiac or abdominal visceral pain still have the paresthesia localized to the appropriate thoracic or abdominal dermatomes, respectively [51-53].

In patients with occipital neuralgia, or other headaches that are focused over the occiput, ONS produces a clear concordant paresthesia; to wit, the patient perceives the paresthesia over the C1-2-3 distribution, which is the same area where they feel the pain. The same holds true for patients with neuropathic pain centered over the supraorbital region that is treated by a supraorbital stimulator. Thus, all of the studies related to treating occipital neuralgia with ONS and the various localized trigeminal neuralgias with SONS/IONS should be understood from the standpoint that they are all simply following the historical standard of concordant paresthesia. Indeed, as noted, their relative high reported success rates of 70-100 \% (avg. $89 \%$ ) are very much in line with analogous studies involving concordant paresthesias for neuropathic pain over the torso and limbs.

While possibly less obvious at first, the issue of paresthesia concordancy holds for some patients with migraine as well. Both Popeney and Oh reported a subset of patients with transformed migraine whose pain was primarily perceived over the occiput $[18,20 \bullet \cdot]$. Further, the reports on ONS for chronic migraine by some of the studies, including the Matharu, Schwedt and Trentman reports, explicitly noted that most, if not all, of their patients had pain that was prominent over the occipital region $[35,38,54 \bullet \cdot]$. Thus, while all of these groups were evaluating migraine responsiveness to ONS, the patients so studied had pain primarily focused over the occiput, and thus followed the historical standard of a concordant paresthesia.

Most migraine headaches, however, are experienced over the frontotemporal regions, and in these cases, ONS produces a non-concordant occipital paresthesia. With that in mind, we believe that Dodick's 2003 report on the use of ONS for cluster headaches was a true watershed event, as it was the first report in the history of neurostimulation and pain to document the successful treatment of a patient in pain with a non-concordant paresthesia. As it was unprecedented, it presented a challenge to understand how stimulating the occipital nerves could ease pain over the distant trigeminal nerves. Now, its unprecedented nature notwithstanding, the extensive series of reports succeeding to Dodick's convincingly demonstrated that ONS did ease migraine pain in some patients. On the other hand, the accumulated database is also persuasive that the associated response rates consistently fall below those groups treated with a concordant paresthesia, e.g., occipital neuralgia treated with an occipital stimulation. As summarized in the tables, whereas over $90 \%$ of patients respond to NS systems producing a concordant paresthesia, less than $40 \%$ of patients with chronic migraine will do so (considering the benchmark double blinded studies).

\section{Clinical Outcome Studies Analysis}

The results of the significant studies on PNS and headaches are summarized in the tables, which divide the patient treatment groups into two: those implanted with systems that produce a concordant paresthesia, e.g., ONS for occipital neuralgia (Table 1), and those that produce a non-concordant paresthesia, e.g., occipital stimulation for the pain of migraine headaches perceived over the trigeminal fields (Table 2). Contrasting the results from the "concordant" group against those of the "non-concordant" group reveals a striking difference in the response rates, and one that pivots on the single variable of paresthesia concordancy.

All five individual "concordant paresthesia" groups of Table 1 reported very high and consistent response rates ( $88 \%, 89 \%, 89 \%, 98 \%$ and $100 \%$, respectively) for an overall response rate of $93 \%$. These results stand in sharp contrast to those found in Table 2, which are those of the groups studying implants that produce non-concordant paresthesias, which overall found less than a $40 \%$ response rate. Close scrutiny of the results of the benchmark Medtronic, Boston Scientific and St. Jude ONS studies suggests that they all actually confirmed minimal to no response of patients with chronic migraine to ONS. From that respect, not only did both the St. Jude and Boston studies fail to show a significant therapeutic response, Medtronic's report of a $39 \%$ rate still did not meet the historical, clinical standard of only counting patients with $50 \%$ or more improvement as responders.

It is this dramatic difference in the observed success rates that provides such compelling support for the central importance of paresthesia concordancy.

\section{Considerations on Mechanisms of Action}

Questions arise as to how to best understand why ONS may be less effective for migraine headaches than for occipitally focused headaches; or alternatively, why combined stimulation of both the occipital and the trigeminal branches may achieve improved results for patients experiencing migraine pain in either a hemicephalic or global distribution. These questions should first be considered from the context of our current understanding of the related functional neuroanatomy, where interest has thus far largely centered on the trigeminocervical complex (TCC) and potentially related higher central nervous system (CNS) centers. Though the data remains quite limited, it does provide some insights.

The TCC is formed by the caudal trigeminal nucleus and portions of the upper three cervical dorsal horns. 
Nociceptive afferents from both the trigeminal nerve and the occipital nerves (C1-2-3) partially converge on the same second order neurons in the TCC, and thus to a final common pathway to higher centers for cephalic nociception and modulation [55••, 56-58]. Bartsch and Goadsby's meticulous animal studies convincingly demonstrated both this discrete convergence, as well as subsequent sensitization of second-order TCC neurons following a sensory barrage, findings that likely underlie the clinical observation of referred pain seen with primary headaches $[55 \bullet \bullet, 56]$. In 2003, Popeney suggested that the TCC may be the neuroanatomical substrate underlying the clinical issue of paresthesia concordancy $[20 \bullet \bullet]$.

There is also early but convincing evidence for the involvement of higher CNS centers with neuromodulation. Utilizing positron-emission tomography (PET scans), in 2003 Matharu documented responsiveness of some of these higher centers to ONS. Paresthesia-correlated activation was observed in the cuneus, pulvinar and anterior cingulate cortex. Activation of the rostral dorsal pons demonstrated a coverable response with pain scores and may be particularly important in the genesis of chronic migraine [54••]. More recently, Magis documented similar PET scan findings in patients with chronic cluster headaches [59].

One potential mechanism accounting for the responsiveness of frontal pain to a distant occipital paresthesia relates to the experimentally confirmed observation that chronic occipital pain may ultimately refer to the frontal regions, and thus globalize [57, 58, 60,61]. This implies that there is a subset of patients with holocephalic headaches, whose pain originated in the occipital region and only over time globalized, thus explaining therapeutic responses to treatments aimed at the occiput, the actual source of the problem. In 1992, Anthony found that $48 \%$ of patients with idiopathic migraine headaches, and thus a frontal pain component, responded to occipital nerve blocks and concluded that the frontal component of the pain was referred [62]. Thus, experimental evidence of referred occipital pain, combined with the proposed possible substrate at the TCC, provides a conceptual framework for a potential mechanism in some patients with frontotemporal migraine pain to therapeutic occipital measures, in the sense that these measures are indeed focused on the actual source of the referred pain.

\section{Clinical Approach}

General

The typical patient being considered for a neurostimulator implant has debilitating, chronic headaches and has been under the care of an experienced headache specialist for months or years. Commonly, the headaches were under good control for a period, but ultimately became chronic and refractory to all reasonable measures, at which point the patient becomes a candidate for trial neurostimulation. Following a successful trial, the permanent unit (10-year battery life span) is implanted. Postoperatively, most all patients report virtually immediate relief from their headaches, and ultimately marked reductions in medication requirements; improvement in their overall sense of well-being, and associated marked increases in their and energy and activity levels. The system is easily maintained, and patients find that they are able to return to family life, work and social interactions.

\section{Candidacy}

In general, a patient is considered a candidate for evaluation for a PNS if they have severe, chronic headaches that have failed to respond to more conservative measures. While there are no strict criteria for candidacy, reasonable guidelines include:

- Chronic, debilitating headaches

- Failed extended course (>3-6 mo) of more conservative management

- Passed psychological prescreening

- Either on no, or minimal and stable, doses of narcotics

Issues that generally do affect candidacy include:

- Headache diagnosis-PNS has been studied and found effective in various types of headaches, including migraine, cluster, hemicranias continua, chronic daily headache, transformed migraine, tension type headaches, occipital neuralgia, post-traumatic headaches and cervicogenic headaches, amongst others.

- Gender

- Age —our implanted group's ages range from 14 to 72 and include 25 adolescents

\section{Trial Stimulation}

The specific techniques involved in placement of both the trial and permanent units have been well described in the literature and will not be reviewed here.

The trial stimulator is percutaneously implanted in the outpatient setting. Upon recovery, the patient is instructed in the operation of the programmable battery and discharged. During the next five days, the patient is advised to test the unit under all practical circumstances, including work, play, travel, etc. The patient returns typically five days later for removal of the unit and evaluation of the results.

A trial PNS is very reliable in predicting the results of the permanent unit. While false-positives may occur, the fact is that less than $2 \%$ of patients ever return after a permanent unit, complaining of loss of efficacy and requesting removal. The underlying reason for this reliability largely relates to 
the typically dramatic nature of the response-one way or the other. That is, most patients typically report either a markedly positive response, often describing near complete resolution of the headaches, or they tend to virtually not respond at all. While of course possible, it is in practice rather unusual for a patient to be "unsure" as to whether or not the trial stimulator effectively eased their pain. From a different viewpoint, the trial period is showing the patient what they can expect with a permanent unit. In this sense, the trial is quite truly a "test drive" of a neurostimulator, such that the patient knows before the permanent implant exactly what they can expect with the unit. It is one of the few times in medicine that there is indeed a test to see how well a patient will do with a specific surgical treatment that is available before the patient has the surgery.

At the conclusion of the trial period, the patient is seen in the office where the unit leads are removed and the response evaluated. While the minimum requirement for a positive response is over $50 \%$ improvement, the majority of responders describe $80 \%$ to over $95 \%$ improvement. For patients finding a positive response and desirous of proceeding, the permanent implant is scheduled.

\section{Permanent Implant}

A permanent stimulator involves the placement of an implantable pulse generator (IPG) and from 1 to 4 leads based upon the patients headache, pain location and trial results (Fig. 1). This is a relatively straightforward surgical procedure that is accomplished either as an outpatient or with an overnight stay.

\section{Recovery}

As all incisions are relatively superficial, recovery and resumption of activity is fairly rapid. Most patients are able to resume normal activities, including travel, within 2-3 days. Those who have sedentary work positions may return to work within a week. Patients should avoid extreme physical activity for the full recovery period of 6 weeks, at which point all restrictions are removed.

\section{Life with a Neurostimulator}

Following the 6-week recovery period, the most remarkable thing about managing a stimulator is how simple it is. The only maintenance required involves the simple process of twice weekly recharging their unit, which involves simply sitting next to a portable recharging unit (RF couple) for an hour. Following the initial 6-week recovery period, we often have patients return to the office on an as needed basis only. Thus, from the patient's standpoint, most everything improves.

- Medication requirements-almost invariably meds markedly decrease, corresponding to the improvement pain. Over $30 \%$ of patients no longer require any routine meds, and most of the rest see marked reductions.

- Psychological status - typically marked improvement in any related issues such as anxiety or depression, with a concomitant improvement in sense of well-being

- Activity level

- No longer frequenting medical facilities or having to stay in due a headache, patients are able to fully return to normal activities of daily living, including interacting with the family and enjoying social occasions.

- Further, we impose absolutely no activity restrictions. We have patients that returned to, or became involved with, various strenuous physical activities, including all forms of exercise, gymnastics, horseback riding, martial arts, baseball, and skiing, without problems.

\section{Risks and Adverse Events}

PNS for head pain is generally considered to be very safe over the long term. In practical terms, complications are uncommon

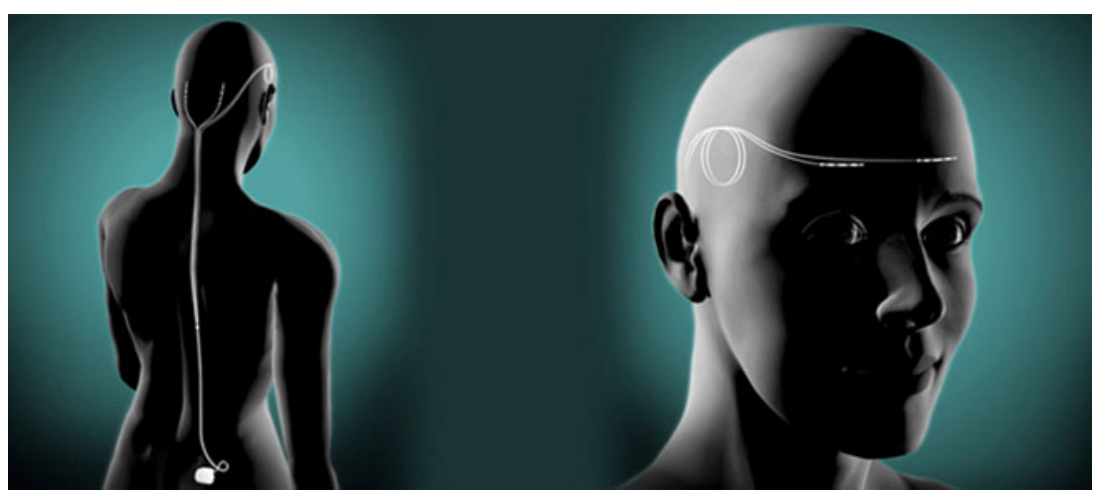

Fig. 1 Schematic depiction of a subcutaneously implanted combined occipital and supraorbital nerve stimulator. A standard implant is presented with the battery (IPG) located in the upper, outer gluteal region. a. From the IPG, four leads are passed subcutaneously such that two of the active terminal arrays are positioned over the greater occipital nerves. b. Two leads are passed over the ear to final subcutaneous positions of the terminal arrays over the supraorbital nerves. Standard strain-relief loops are depicted over the ear and at the IPG 
and are largely limited to a small (3-6\%) risk of infection. However, given the subcutaneous location of the systems, any infections are superficial and invariably respond to antibiotics, and usually with temporary explant of the device. We are unaware of any reports in these patient groups of serious complications that have resulted in long-term morbidity.

Other clinical considerations here relate to technical issues due the nature of the implant, and include lead migration or fracture and IPG malfunction, and though frustrating, are easily remedied with a short outpatient procedure.

\section{Conclusion}

Following our initial introduction of ONS for occipital neuralgia in 1999, a plenitude of clinical reports both confirmed our initial findings and also initially extended the methodology to the frontal region and the trigeminal neuralgias, and then ultimately to primary headaches, particularly clusters and chronic migraine. Indeed, virtually all extant reports find a therapeutic response to PNS with minimal downside, and when considered together with the basic science research, provide a coherent, consistent and substantive basis for PNS treatment for the cephalic neuropathic pain disorders, as well as for primary headaches. While there are many clinical and foundational issues to address going forward, the database supports an optimistic vision for the future of implanted peripheral nerve stimulation and head pain. In considering that future, we again emphasize the compelling evidence that supports moving towards considering paresthesia concordancy, both when planning system implants for individual patients, as well as for future research protocols.

Disclosure No advice, direction, or assistance (financial or otherwise) was received for this paper. Prior to 3 years ago, the author served as a consultant to St. Jude Medical and is part of the author group that is just now presenting the results of St. Jude's completed multicenter study on occipital neurostimulation and migraine headaches.

Open Access This article is distributed under the terms of the Creative Commons Attribution License which permits any use, distribution, and reproduction in any medium, provided the original author(s) and the source are credited.

\section{References}

Papers of particular interest, published recently, have been highlighted as:

- Of importance

•. Of major importance

1. Stang PE, Osterhaus JT. Impact of migraine in the United States: data from the National Health Interview Survey. Headache. 1993;33:29-35.
2. Bigal ME DS, Reed M, Lipton RB. Chronic migraine in the population: burden, diagnosis, and satisfaction with treatment. Neurology. 2008;71:559-66.

3. Melzac R, Wall PD. Pain mechanisms: a new theory. Science. 1965;150:971-8.

4. Long DM, Erickson D, Campbell J, North R. Electrical stimulation of the spinal cord and peripheral nerves for pain control; a 10-year experience. Appl Neurophysiol. 1981;44:207-17.

5. Krames E. Spinal cord stimulation: indications, mechanism of action, and efficacy. Curr Rev of Pain. 1999;3:419-26.

6. Campbell J, Long DM. Peripheral nerve stimulation in the treatment of intractable pain. J Neurosurg. 1976;45:692-09.

7. Nashold BS, Goldner JL. Electrical stimulation of peripheral nerves for relief of intractable chronic pain. Med Instrum. 1975;9:224-5.

8. Nashold BS, Goldner JL, Mullen JB, Bright DS. Long-term pain control by direct peripheral nerve stimulation. J Bone Joint Surg Am. 1982;64:1-10.

9. Picaza JA, Cannon BW, Hunter SE, et al. Pain suppression by peripheral nerve stimulation: part II. Observations with implanted devices. Surg Neurol. 1975;4:115-26.

10. Picaza JA, Hunter SE, Cannon BW. Pain suppression by peripheral nerve stimulation. Appl Neurophysiol. 1977;40:223-34.

11. Waisbrod G, Panhans C, Hansen D, Gerbershagen HU. Direct nerve stimulation for painful peripiheral neuropathies. J Bone Joint Surg Am. 1985;67-B:470-2.

12. •• Weiner RL, Reed KL. Peripheral neurostimulation for control of intractable occipital neuralgia. Neuromodulation. 1999;2:217-21. This article is the first presentation of percutaneous placement of occipital nerve stimulator leads and initiated the current interest in this methodology.

13. Ghaemi K, Capelle HH, Kinfe TM, Krauss JK. Occipital nerve stimulation for refractory occipital pain after occipitocervical fusion: expanding indications. Stereotact Funct Neurosurg. 2008; 86:391-3.

14. Hammer M, Doleys D. Perineuronal stimulation in the treatment of occipital neuralgia: a case study. Neuromodulation. 2001;4:47-51.

15. Johnstone CS, Sundaraj R. Occipital nerve stimulation for the treatment of occipital neuralgia-eight case studies. Neuromodulation. 2006;9:41-7.

16. Kapural L, Mekhail N, Hayek SM. Occipital nerve electrical stimulation via the midline approach and subcutaneous surgical leads for treatment of severe occipital neuralgia: a pilot study. Anesth Analg. 2005;101:171-4.

17. Melvin EA, Jordan ER, Weiner RL, Primm D. Using peripheral nerve stimulation to reduce the pain of $\mathrm{c} 2$-mediated headaches: a preliminary report. Pain physician. 2007;10:453-60.

18. Oh MY, Ortega J, Bellotte JB, et al. Peripheral nerve stimulation for the treatment of occipital neuralgia and transformed migraine using a c1-2-3 subcutaneous paddle style electrode: a technical report. Neuromodulation. 2004;7:103-12.

19. • Paemeleire K, Van Buyten JP, Van Buynder M, et al. Phenotype of patients responsive to occipital nerve stimulation for refractory head pain. Cephalalgia. 2010;30:662-73. This is the first group to specifically evaluate the responsiveness of patients to occipital nerve stimulation based on their phenotypes and diagnosistic categories.

20. •• Popeney CA, Aló KM. Peripheral neurostimulation for the treatment of chronic, disabling transformed migraine. Headache. 2003;43:369-75. This report and Dodick's 2003 report on ONS in a patient with cluster headaches were the first two to utilize PNS as a treatment for primary headache disorders. Prior to this, all applications were for occipital neuralgia and other cephalic neuropathic pains.

21. Rodrigo-Royo D, Azcona J, Quero J, et al. Peripheral neurostimulation in the management of cervicogenic headache: four case reports. Neuromodulation. 2005;8:241-8. 
22. - Slavin KV, Colpan ME, Munawar N, et al. Trigeminal and occipital peripheral nerve stimulation for craniofacial pain: a single-institution experience and review of the literature. Neurosurg Focus. 2006;21:E5. This is one of the definiting articles on the use of PNS for various cephalic neuralgias by a leading expert in the field.

23. Dunteman E. Peripheral nerve stimulation for unremitting opthalmic posherpetic neuralgia. Neuromodulation. 2002;5:279-90.

24. Amin S, Buvanendran A, Park KS, et al. Peripheral nerve stimulator for the treatment of supraorbital neuralgia: a retrospective case series. Cephalalgia. 2008;28:355-9.

25. Johnson MD, Burchiel KJ. Peripheral stimulation for treatment of trigeminal postherpetic nerualgia and trigeminal postherpetic pain: a pilot study. Neurosurgery. 2004;55:135-42.

26. Yakovlev AE, Resch BE. Treatment of chronic intractable atypical facial pain using peripheral subcutaneous field stimulation. Neuromodulation. 2010;13:137-40.

27. Stidd DA, Wuollet A, Bowden K, et al. Peripheral nerve stimulation for trigeminal neuropathic pain. Pain physician. 2012;15:27-33.

28. •- Dodick DW. Occipital nerve stimulation for chronic cluster headache. Advanced Studies in Medicine. 2003;3:S569-71. This article represents a pivital point in the history of neuromodulation and head pain, as it was the first to describe a treatment response to PNS in a patient with a primary headache disorder. Its significance increases as it is also the first article in the history of neuromodulation that presents a therapeutic response by a nonconcordant paresthesia, i.e., stimulation of the occipital nerves for pain perceived over the trigeminal system.

29. de Quintana-Schmidt C, Casajuana-Garreta E, Molet-Teixido J, et al. Stimulation of the occipital nerve in the treatment of drugresistant cluster headache. Rev Neurol. 2010;51:19-26.

30. Fontaine D, Christophe Sol J, Raoul S, et al. Treatment of refractory chronic cluster headache by chronic occipital nerve stimulation. Cephalalgia. 2011;31:1101-5.

31. Magis D, Allena M, Bolla M, et al. Occipital nerve stimulation for drug-resistant chronic cluster headache: a prospective pilot study. Lancet Neurol. 2007;6:314-21.

32. Magis D, Gerardy PY, Remacle JM, Schoenen J. Sustained effectiveness of occipital nerve stimulation in drug-resistant chronic cluster headache. Headache. 2011;51:1191-201.

33. Magis D, Schoenen J. Occipital nerve stimulation for intractable chronic cluster headache: new hope for a dreadful disease? Acta Neurol Belg. 2011;111:18-21 [abstract].

34. Mueller OM, Gaul C, Katsarava Z, et al. Occipital nerve stimulation for the treatment of chronic cluster headache-lessons learned from 18 months experience. Central European neurosurgery. 2011;72:84-9.

35. Schwedt TJ, Dodick DW, Hentz J, et al. Occipital nerve stimulation for chronic headache-long-term safety and efficacy. Cephalalgia. 2007;27:153-7.

36. Schwedt TJ, Dodick DW, Trentman TL, Zimmerman RS. Occipital nerve stimulation for chronic cluster headache and hemicrania continua: pain relief and persistence of autonomic features. Cephalalgia. 2006;26:1025-7.

37. Trentman TL, Rosenfeld DM, Vargas BB, et al. Greater occipital nerve stimulation via the Bion microstimulator: implantation technique and stimulation parameters. Clinical trial: NCT00205894. Pain physician. 2009;12:621-8.

38. Trentman TL, Zimmerman RS, Seth N, et al. Stimulation ranges, usage ranges, and paresthesia mapping during occipital nerve stimulation. Neuromodulation. 2008;11:56-61.

39. Serra G, Marchioretto F. Occipital nerve stimulation for chronic migraine: a randomized trial. Pain physician. 2012;15:245-53.

40. • Lipton RB, Goadsby PJ, Cady RK, et al. PRISM study: occipital nerve stimulation for treatment-refractory migraine [abstract]. Cephalalgia. 2009;29:30. One of the three studies supported by the three large manufacturers; lead by Lipton, it found no significant difference in migraine patients treated with ONS.

41. •• Silberstein SD, Dodick D, Saper, J, et al. Safety and efficacy of peripheral nerve stimulation of the occipital nerves for the management of chronic migraine: results from a randomized, prospective, multicenter double-blinded, controlled study. Cephalalgia. 2012; In press. Another extremely well constructed multicenter, randomized, double blinded prospective investigation. While the primary variable (VAS) did not reach statistical significance, several others did - most notably a significant response in postiive patient responses over the duration of the study (over $50 \%$ improvement in pain or HA days).

42. • Saper JR, Dodick DW, Silberstein SD, et al. Occipital nerve stimulation for the treatment of intractable chronic migraine headache: ONSTIM feasibility study. Cephalalgia. 2011;31:271-85. This article reports Medtronic's study group's finding of a statistically significant $40 \%$ response rate to ONS for patients with chronic migraine. Along with St. Jude's reporrt, this was a well construcgte, multicenter, randomized, double blinded prospective evaluation.

43. - Narouze SN, Kapural L. Supraorbital nerve electric stimulation for the treatment of intractable chronic cluster headache: a case report. Headache. 2007;47:1100-2. This article describes the first application of supraorbital nerve stimulation alone for cluster headaches.

44. • Vaisman J, Markley H, Ordia J, Deer T. The treatment of medically intractable trigeminal autonomic cephalalgia with supraorbital/supratrochlear stimulation: a retrospective case series. Neuromodulation. 2012;15:374-80. Recent article that continued the work of Narouze (43 above) noting similar results.

45. • Reed KL, Black SB, Banta CJ, Will KR. Combined occipital and supraorbital neurostimulation for the treatment of chronic migraine headaches: initial experience. Cephalalgia. 2010;30:260-71. This was the first report on the use of "combined occipital nerve and supraorbital nerve" neurostimulation for chronic migraine headaches. Dramatic results were reported in the series of seven patients, with six describing near complete resolution of the pain and associated neurological findings.

46. - Deshpande KK, Wininger KL. Feasibility of combined epicranial temporal and occipital neurostimulation: treatment of a challenging case of headache. Pain physician. 2011;14:37-44. This is the first report on combined cephalic neurostimulation since our original article (45 above).

47. • Mammis A, Gudesblatt M, Mogilner AY. Peripheral neurostimulation for the treatment of refractory cluster headache, long-term followup: case report. Neuromodulation. 2011;14:432-5. Another recent article on the use of combined neurostimulation for primary headaches. Here the authors applied occipital nerve, supraorbital nerve and infraorbital nerve stimulation in a patient with cluster headaches.

48. - Linder S. Combined occipital/supraorbital nerve stimulation for treatment of refractory headaches: initial adolescent experience (ages 12-17) [abstract]. Headache. 2011;51:47. This abstract represents the first description of the use of combined ONS-SONS in a group of adolescents with findings of very good results over the long term.

49. - Datta S, Reed KL, Will KR. Combined supraorbital and occipital nerve stimulation in failed surgical treatment of migraine: case report and review of the literature [abstract]. Presented at American Society of Intervention Pain Physicians 2012 Annual Meeting; 2011; Washington DC: Pain Physician, 2011. This interesting abstract presentation described the first application of combined ONS-SONS in a patient with severe chronic migraine that was post unsuccessful surgical occipital nerve decompression.

50. • Reed KL, Will KR, Chapman J, Richter E. Combined occipital and supraorbital neurostimulation for chronic migraine headaches: an extended case series [abstract]. Presented at 15th Congress of the International Headache Society; 2011; Berlin, Germany: Cephalalgia, 2011: 98-99. This poster abstract 
represents the largest report thus far on patients treated with combined ONS-SONS.

51. Hautvast RW, Horst GJ, DeJong BM, et al. Relative changes in regional cerebral blood flow during spinal stimulation in patients with refracgtory angina pectoris. Eur J Neuro. 1997;9:1178-83.

52. Khan YN, Raza S, Khan E. Spinal cord stimulation in visceral pathologies. Pain Medicine. 2006;7:121-5.

53. Linderoth B, Foreman RD. Physiology of spinal cord stimulation: review and update. Neuromodulation. 1999;2:150-64.

54. •• Matharu MS, Bartsch T, Ward N, et al. Central neuromodulation in chronic migraine patients with suboccipital stimulators: a pet study. Brain. 2004;127:220-30. This is another pivital report, as it was the first to describe brain PET scan changes in patients with migraine headaches treated with ONS. It was the first to confirm regional blood flow changes in some of the deep nuclei related to migraine genesis and modulation due to ONS.

55. • Bartsch T, Goadsby PJ. Stimulation of the greater occipital nerve induces increased central excitability of dural afferent input. Brain. 2002;125:1496-509. This article, along with the three below by Bartsch and Goadsby, describes the microanatomic findings at the trigeminocervical complex that forms the primary basis for our current understanding of this complex.

56. Bartsch T, Goadsby PJ. Increased responses in trigemocervical nociceptive neurons to cervical input after stimulation of the dura mater. Brain. 2003;126:1801-13.

57. Bartsch T, Goadsby PJ. The trigeminocervical complex and migraine: current concepts and synthesis. Current pain and headache reports. 2003;7:371-6.

58. Bartsch T, Goadsby PJ. Anatomy and physiology of pain referral patterns in primary and cervicogenic headache disorders. Headache Curr. 2005;2:42-8.
59. Magis D, Bruno MA, Fumal A, et al. Central modulation in cluster headache patients treated with occipital nerve stimulation: an FDG-PET study. BMC Neurol. 2011;11:25.

60. Bogduk N. The clinical anatomy of the cervical dorsal rami. Spine. 1982;7:318-30.

61. Bogduk N. Cervicogenic headache: anatomic basis and pathophysiologic mechanisms. Current pain and headache reports. 2001; 5:382-6.

62. Anthony M. Headache and the greater occipital nerve. Clin Neurol Neurosurg. 1992;94:297-301.

63. Slavin KV, Nersesyan H, Wess C. Peripheral neurostimulation for treatment of intractable occipital neuralgia. Neurosurgery. 2006; 58:112-9.

64. Shaladi A, Crestani F, Saltari R, Piva B. Percutaneous electrical nerve stimulation of peripheral nerve for the intractable occipital neuralgia. Recenti progressi in medicina. 2008;99:295-301.

65. Magown P, Garcia R, Beauprie I, Mendez IM. Occipital nerve stimulation for intractable occipital neuralgia: an open surgical technique. Clin Neurosurg. 2009;56:119-24.

66. Vadivelu S, Bolognese P, Milhorat TH, Mogilner AY. Occipital nerve stimulation for refractory headache in the Chiari malformation population. Neurosurgery. 2012;70:1430-7.

67. Simopoulos T, Bajwa Z, Lantz G, et al. Implanted auriculotemporal nerve stimulator for the treatment of refractory chronic migraine. Headache. 2010;50:1064-9.

68. Burns B, Watkins L, Goadsby PJ. Treatment of hemicrania continua by occipital nerve stimulation with a bion device: long-term follow-up of a crossover study. Lancet Neurol. 2008;7:1001-12.

69. Burns B, Watkins L, Goadsby PJ. Treatment of intractable chronic cluster headache by occipital nerve stimulation in 14 patients. Neurology. 2009;72:341-5. 